\title{
A POLÍTICA, A PROPAGANDA E O ENSINO DA HISTÓRIA
}

\author{
Luis Fernando Cerri*
}

RESUMO: Discute-se o significado da publicidade na sociedade contemporânea e seu relacionamento com a constituição da consciência histórica da população, por meio da aprendizagem histórica. Argumenta-se também que a publicidade é um documento precioso para a pesquisa e o ensino da história. O exemplo proposto é a publicidade com tema histórico (Independência do Brasil) no período do "milagre econômico brasileiro" (1969-1973).

Palavras-chave: Publicidade. Consciência histórica. Aprendizagem histórica. Comemorações da Independência do Brasil.

\section{Politics, ADVERTISEMENT AND HISTORY TEACHING}

ABSTRACT: This paper discusses the meaning of advertisement in the contemporary society and its relationship to the historical awareness of the people, through history learning. It also argues that advertisements are a precious document for History research and teaching. An illustration of this is an advertisement recurring to a historical theme (the Independence of Brazil) during the "Brazilian Economical Miracle" (1969-1973).

Key words: Advertisement. Historical awareness. History learning. Commemorations of the independence of Brazil.

\footnotetext{
* $\quad$ Doutor em Educação pela Universidade Estadual de Campinas (UNICAMP) e professor do Departamento de História e do Mestrado em Educação da Universidade Estadual de Ponta Grossa (UEPG) E-mail: Ifcerri@uepg.br.
}

Disponível em <http://www.cedes.unicamp.br> 
enho na porta do meu armário de trabalho um prospecto de consórcio de veículos, com uma bela motocicleta estampada e os dizeres "Liberdade em suaves prestaçôes". Foi parar na porta do armário pelas minhas mãos mesmo, num período de alta intensidade de trabalho; era uma mensagem aos colegas e passantes, de que o ritmo e as condições de trabalho estavam a cobrar um outro mundo, em que pudéssemos usufruir o sonho de jogar tudo para o alto e sair para algum lugar prazeroso, dotado de uma máquina capaz de oferecer a liberdade. Era ao mesmo tempo uma ironia com o trabalho que desenvolvi na tese de doutoramento, referente à propaganda e o ensino de história. Em suma, ao mesmo tempo em que - mortal como todo mundo - colocava-me participante do jogo de sedução da publicidade, troçava com a impossibilidade daquele consórcio me vender aquilo que ele prometia: ia vender-me em prestaçóes suaves a motocicleta, mas a liberdade escaparia por entre os dedos como fumaça, assim que eu chegasse na segunda-feira, no emplacamento, impostos, combustível, manutençãa, a prestação no orçamento doméstico.

A propaganda ${ }^{1}$ fala-nos às nossas necessidades imediatas: comer, vestir, deslocar-se, descansar, beber, ainda que com diferentes graus de sofisticação. Mas via de regra faz isso por meio dos desejos que coletivamente nutrimos e que socialmente nos autorizamos a realizar ou pelo menos a continuar desejando (e com isso movendo as nossas vidas em determinados sentidos). E vende, portanto, não apenas macarrão instantâneo em copo, mas também a integração social com os demais jovens; não apenas uma calça, mas a aceitação no grupo e/ou o sucesso sexual e assim por diante. Compram-se, com as coisas, valores pessoais e sociais, idéias, símbolos. Compram-se pedaços de humanidade entremeados nos objetos e serviços. E o sistema funciona tão bem que chegamos a comprar símbolos que nos permitem acreditar que estamos livres do condicionamento imposto pela mercantilização de tudo.

No jogo de superposição de significados sociais e segundos às coisas constitui-se a mercadoria: o fetichismo esconde nas relaçôes de valor o trabalho e as próprias relaçôes de trabalho, que envolvem a relação entre as classes. No fundo, a metáfora do fetichismo é uma imagem - cara a Marx e ao Romantismo em sua época - do aprendiz de feiticeiro ou do Dr. Frankenstein, cujas criações passam à condição de sujeitos e fogem do controle dos criadores, passando a oprimi-los. No período em que Marx (1985) escreveu sobre esse tema ele ainda não podia avaliar as dimensões que a propaganda acabou tomando no século XX, ou seja, a de uma in- 
dústria em grande escala cujo produto principal é a agregação de valor aos produtos que vende. Uma vez tomada como elemento do conjunto da sociedade capitalista em que vivemos, a propaganda pode ser compreendida também como expressão da época em que ocorre e, portanto, como uma fonte histórica de primeira ordem, principalmente se o que temos em mente é pesquisar o recorte da realidade para o qual ela se dirige, isto é, os sonhos, desejos, as expectativas das pessoas, isoladas ou em grupos, às quais os anúncios se dirigem para satisfazer e criar necessidades. É por vender mais do que produtos ou serviços que a propaganda acaba por tornar-se uma referência fundamental para o estudo do imaginário. Considerando, portanto, que em sala de aula estamos buscando cada vez mais recortes do real que sejam significativos para os alunos e que permitam extrapolar os meros registros da história política e militar da nação, o trabalho com a propaganda aparece como um importante aliado.

\section{Usos da propaganda no ensino da história e das humanidades}

O primeiro cuidado para esse uso do material publicitário no ensino de história e das humanidades em geral é considerar a sua historicidade, que é exatamente o nexo mais interessante para o professor e o pesquisador que têm como tema determinada época/espaço no passado. O professor pode, por exemplo, propor aos alunos as conseqüências, em cada época, de uma troca das peças publicitárias analisadas (como se a do presente fosse feita no início do século e vice-versa); pode estimular seus alunos a listar todo o quadro que envolve cada um dos períodos, como os fatores técnicos (jornal feito por linotipia x jornal com impressão de alta resolução e colorido, agilidade ou demora na mudança das campanhas publicitárias) e culturais (atitude perante a seminudez e a sugestão sexual, perspectivas de futuro, condiçōes de saúde e ideais de beleza); pode, enfim, encontrar outras portas de entrada para o conhecimento histórico nos períodos sugeridos pelos currículos e programas.

Uma outra perspectiva é a da utilização da propaganda como reflexão sobre o nosso próprio tempo. Evidentemente, esse uso não está isolado da prospecção da propaganda do passado, nem deve renegar necessariamente uma abordagem temporal mais extensa: o que se aponta é a possibilidade de calcar o presente como foco de interesse imediato, que pode e deve encaminhar para a busca das fontes que informem uma reflexão que traga o passado representado pela propaganda. Essa trilha pode 
iniciar-se com uma abordagem sobre os hábitos de consumo dos alunos da turma e suas famílias, transformando em objeto de reflexão um conjunto de atos que geralmente não é notado, propiciando o questionamento das próprias escolhas. Em geral, essas escolhas de consumo são irrefletidas, ficando na superfície de tópicos como a relação custo-benefício, qualidade, satisfação de uma necessidade sem que se pense como ela se estabeleceu de forma tão irrecorrível etc. Um cuidado, portanto, a levar em conta nesse trabalho é o de ultrapassar os meros limites de uma educação para o "Trabalho e Consumo" (conforme os PCNs), ou seja, da formação de um consumidor que zela pelos seus direitos para que o sistema funcione "corretamente". Transcender esse aspecto é ter clareza de que a educação não pode estar limitada à adaptação do educando ao mundo tal como ele é, mas contribuir para que as razôes profundas das "coisas como estão" sejam vislumbradas e interpretadas, bem como para que haja possibilidade de pensar alternativas, pensar este que parte da idéia essencialmente histórica de que o pensamento se debruça sobre o mundo tal como está, e não tal como é.

Sem uma abordagem doutrinadora - que no mais é nociva ao processo de desenvolvimento do educando, pois dá as respostas antes das perguntas e das elaborações do aluno - é possível estabelecer um diálogo sobre a estruturação do próprio sujeito a partir do seu querer. Para isso, cada peça publicitária estudada pode ser pensada a partir da experiência de cada um, observando como a publicidade disputa as estruturas já existentes de necessidades e como ela cria outras necessidades; como, enfim, isso se relaciona com o mundo da produção e da dominação de classes. A busca é por refletir sobre a construção histórica do próprio sujeito e das relações intersubjetivas. Esse tipo de atividade pode contribuir, enfim, para o processo de retomada do sujeito que se perdeu em meio a subjetivação dos objetos típica do capitalismo.

Uma nuance desses dois primeiros tipos de trabalho com a propaganda, que foram mencionados até aqui, é a abordagem dos materiais publicitários buscando a decifração do apelo à adesão a determinadas idéias e formas de pensar a sociedade, mais que do apelo à compra de produtos e serviços (ou, ainda, subjacente a esse apelo). Trata-se da pesquisa específica das idéias que estabelecem um duplo movimento com a propaganda: as que, já existindo, são aproveitadas e reforçadas como recurso para a obtenção de sucesso da mensagem publicitária e que, portanto, reforçam as relações sociais tal qual elas são, e as que não existem efetivamente, mas são criadas, disseminadas e alteram as relações sociais. 
Por fim, quero colocar diante do leitor um último tipo de abordagem possível das mensagens publicitárias no processo educativo, que é a observação de como as mesmas ensinam a história a partir de determinados pontos de vista e com determinados objetivos que extrapolam a venda de produtos e idéias e que entram no campo da representação coletiva sobre o que seja a sociedade, suas origens, características e comportamentos normalizados. Esse tipo de abordagem não pode ser pensado isoladamente dos outros já comentados até aqui porque também é venda de idéias e produtos, mas tem como diferencial a matéria-prima do argumento, que é o aproveitamento e recomposição de um conhecimento histórico anteriormente estabelecido e difundido.

Esse trabalho destina-se principalmente às séries finais do ensino fundamental e ao ensino médio, pois envolve uma abstração dentro da outra: de que a propaganda difunde idéias importantes para a reprodução das relações sociais e de que o conhecimento histórico veiculado nessa propaganda não é somente o passado e/ou sua escrita, mas um campo de batalha de definição daquelas tais idéias importantes para a reprodução das relações sociais. Portanto, não se limita a uma narrativa, mas significa também um campo do conhecimento que possibilita criar e modificar identidades grupais, de uma maneira parecida com o que a propaganda faz.

\section{Ferramentas de leitura}

Mais que apontar roteiros fechados, a intenção desse tópico é fornecer elementos para a abordagem e reflexão sobre as peças publicitárias, tomando-as como um conjunto de vários níveis de linguagem e de significados que é preciso mapear antes de qualquer discussão crítica. Por isso, são imprescindíveis ferramentas de análise das mensagens publicitárias, visando um trabalho sistemático com esse tipo de fonte, que supere o impressionismo e seja capaz de operar a partir de categorias que abrangem da linguagem ao conteúdo de cada anúncio.

Uma ferramenta importante de leitura é a obra semiológica de Roland Barthes, que aplica à propaganda um método da lingüística, considerando todos os pontos do percurso da mensagem publicitária: envolve uma fonte de elocução, que é a empresa da qual o produto é lançado, um ponto de recepção, que é o público, e um canal de transmissão, que é o 
suporte da propaganda. Concentrando a atenção no nível da mensagem em si, Barthes propõe analisar semanticamente a constituição do texto publicitário (o que vale também para a imagem entendida como linguagem): se toda mensagem é o encontro de um nível de expressão (ou significante) e um nível de conteúdo (ou significado), uma sentença publicitária contém na verdade duas mensagens, cuja forte imbricação constitui a especialidade da linguagem publicitária (Barthes, 1994). A "primeira" mensagem é constituída pela sentença literalmente, simplesmente traduzida dos sinais gráficos que são as letras, a decifração dos códigos lingüísticos. Essa mensagem não inclui ainda todo o pensamento e a cultura de quem usou esse código, suas metáforas e significados que se superpõem e se sedimentam sobre os fonemas, palavras e expressões. A "segunda" mensagem é uma mensagem total, e deriva sua totalidade do caráter singular do seu significado (este significado é único e sempre o mesmo, em todas as mensagens publicitárias: a excelência do produto anunciado). Quando este significado segundo é percebido, a meta publicitária é atingida. Essas mensagens se relacionam de forma especial: no ato de propaganda, a primeira mensagem torna-se apenas a significante da segunda mensagem. Nesse contexto, o fenômeno de "conotação" é de grande importância, indo além do fenômeno da publicidade em si, ligando-se provavelmente à própria essência da comunicação de massa, da qual não recebemos nada além de mensagens conotadas.

O enfoque de Barthes estabelece uma estrutura própria para leitura das peças publicitárias: a identificação da denotação (que já chamamos de mensagem ou sentido "primeiro" do texto, isto é, a sua apreensão literal, lingüística, de decodificação pura e simples do símbolo, seja ele verbal, sonoro ou imagético), da conotação (o sentido "segundo", aquele que é "pescado" pelo espectador a partir do que, segundo as suas referências culturais, a mensagem "quer dizer") e da referenciação (ou seja, o emissor ou o produto que está sendo oferecido) (Barthes, 1988).

O que é mais importante nesse trabalho de leitura analítica, que pode ser feito coletivamente no ambiente educacional, é desenvolver um leitor crítico, que deve substituir o espectador passivo e que acabará depois por surpreender-se defendendo práticas e portando convicções, cuja origem não conhece, não sabe quando, onde e nem porque estão fazendo parte da sua bagagem. Se isso chega a ocorrer, uma centelha de razão é lançada: o que se fará com ela é uma pergunta cuja resposta se constrói coletiva e pacientemente. 
A propaganda ensinando história de mãos dadas com o poder: um exemplo

Tomaremos aqui um exemplo específico da análise de peças publicitárias com conteúdo histórico, selecionadas das revistas Veja e Visão do início dos anos de 1970. Essa conjuntura é marcada, no plano econômico, por um acelerado crescimento que se vincula a ações estatais de planejamento e abundante disponibilidade de crédito internacional, e no plano político caracteriza-se por um recrudescimento do regime militar, com a vigência de instrumentos que garantem um regime de arbítrio e exceção e uma acentuada concentração de poder no Executivo federal. É um momento de exacerbação do nacionalismo, que funciona articulando o entusiasmo popular com as conquistas econômicas e o direcionamento político conservador e desmobilizador, por parte do Estado, deste entusiasmo nacionalista. Diversas opções são possíveis para interpretar a ação nacionalista/nacionalizante do Estado e de sua base de sustentação na classe dominante, sendo a do controle social uma das mais expressivas. Seguindo essa vertente, pode-se afirmar que o conteúdo histórico presente em algumas peças publicitárias da época tem a função de reforçar esse movimento de integração entre os membros da nação num momento em que ela se modifica aceleradamente e, para muitos, tende a tornar-se irreconhecível. O conhecimento histórico "propagandeado", portanto, teria o papel de opor às forças centrífugas da modernização, atuando sobre a identidade, uma âncora, uma força centrípeta baseada no reforço a uma memória histórica, ao conhecimento de um passado comum, dotado de personagens e símbolos capazes de fornecer a matéria-prima para o sentimento de identificar-se com pessoas que não se conhece, com as quais não se trava relação direta, mas que são entendidas como viventes simultâneas de algo maior, um grupo, um organismo coletivo chamado de nação.

As peças selecionadas referem-se todas a uma retomada e uma reutilização da imagem de D. Pedro I, qualificando-o como centro inconteste da conquista da Independência. É interessante notar que temos aqui uma opção (não necessariamente acordada de maneira formal ou explícita) de narrativa sobre a Independência que não é a única possível. ${ }^{2}$ Em outro momento histórico, o início da República, por exemplo, a opção de narrativa da Independência estabelecia um outro centro, Tiradentes, evitando colocar um representante da monarquia no centro das atençôes. ${ }^{3}$ 
A opção de contar a Independência pelo prisma de D. Pedro é assumida em todas as peças que são apresentadas a seguir, e essa opção tem como característica desenfocar os outros elementos possíveis de interpretação, sem ocultá-los (para que a história não soe à falsidade), mas subsumindo-os à centralidade do monarca e do Sete de Setembro. Não é difícil traçar uma hipótese para essa releitura reabilitadora de D. Pedro: tal como as suas atitudes políticas, o regime militar também se encaminhava com base no princípio de que o grupo dirigente agia corretamente a partir de sua própria genialidade política, calcada numa legitimidade que não admitia contestações e não se curvava aos apelos daqueles que exigiam participar do poder. Enfim, a mentalidade expressa na frase "Tudo farei para o povo, nada porém pelo povo", que por um lado imagina o povo como uma coletividade incapaz de escolher seus rumos e que precisa ser tutelada e, por outro, a assunção, para si mesmo, do papel de condutor inconteste desse povo. Guardadas as proporções, a similitude é muito importante para ser desprezada. Para os que insistiam em questionar os militares no poder, a história era brandida como arma e mostrava que, apesar dos pesares, o pulso firme e a capacidade de pairar sobre os interesses menores e agarrar-se aos interesses "nacionais" (características atribuídas a D. Pedro e à elite político-militar dirigente) garantiam nobres conquistas, como a independência e a integridade territorial, ou "integração nacional" e "Brasil grande". Tiradentes, por outro lado, é um personagem secundário nesse contexto, apesar de não ser ocultado: mesmo sendo representante do menos radical entre os movimentos de independência, sua imagem era muito mais facilmente colável à oposição clandestina ao regime militar (que também combatia um sistema autoritário por fora do sistema legal de sua época) que ao próprio regime (muito mais facilmente comparável à monarquia centralizada de D. Maria I).

A primeira peça publicitária (figura 1) traz uma representação artística do Imperador sobre um corcel, com o gesto de erguer o chapéu, cercado pelo povo e pelos companheiros de cortejo. A peça não indica que se trata de um fragmento do quadro de François-René Moreaux, intitulado "Proclamação da Independência", de 1850. É uma das primeiras representações do Sete de Setembro, embora não a mais consagrada. O texto traz: "Era chegada a hora do cafezinho. Café, 150 anos de divisas. Café solúvel Brasília”. Não termina aí a denotação da peça, que inclui um logotipo no canto inferior direito, no qual a data 1822 liga-se ou torna-se a data de 1972. Uma interpretação possível, para esta e para as demais pe- 
ças, da conotação é o interesse de ligar a própria marca com aquilo que foi estabelecido principalmente pelo Estado como um ritual de identificação entre os brasileiros. A peça significa - como as outras aqui apresentadas antes de tudo uma declaração de participação no grupo de identificação chamado Brasil. Um outro significado é ligado ao significado do cafezinho em nossa cultura, ou seja, um ritual de confraternização, descontração e de pausa ou descanso merecidos: após a concretização de uma grande obra, o merecimento do descanso. A referência às divisas esclarecerá, para o leitor, como a mensagem referencial (Café Solúvel Brasília) afirma participar desse ritual de identificação do Sesquicentenário da Independência: enquanto produtora de café, integra-se aos personagens que possibilitam a aquisição de divisas para o país, o que permite sustentar a independência efetiva.

Figura $1-($ Veja n. 209 , de 6/9/72)

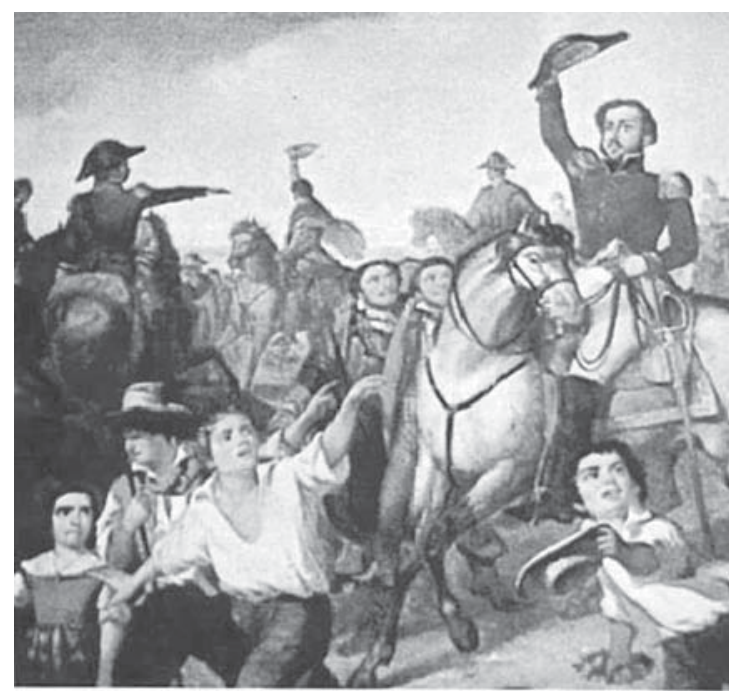

ERA CHEGADA A HORA DO CAFEZINHO

Café, 150 anos de divisas.

CAFE SOIÚVEL GRASIIN

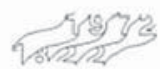

Cad. Cedes, Campinas, vol. 25, n. 67, p. 319-331, set./dez. 2005

Disponível em <http://www.cedes.unicamp.br> 
Figura $2-($ Veja n. 209 , de 6/9/72)

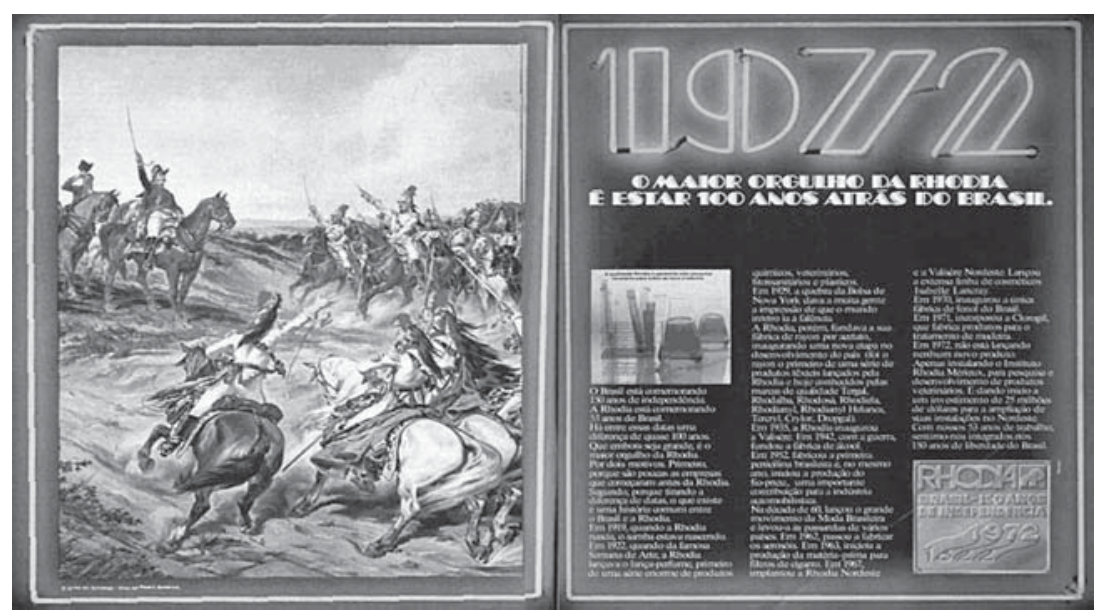

A figura 2 traz um tipo parecido de mensagem de participação da marca na festa da identidade coletiva. A figura é um fragmento, cuja fonte é enunciada: o quadro "O grito do Ipiranga", de Pedro Américo, pintado na segunda metade do século XIX e que pode ser considerado como a representação oficial e mais conhecida do Sete de Setembro. No texto de chamada, essa vontade de fazer parte fica clara: "1972: O maior orgulho da Rhodia é estar 100 anos atrás do Brasil". Em síntese, o corpo do texto afirma que a empresa chegou ao Brasil pouco mais de 100 anos depois da Proclamação da Independência, e traça um inventário cronológico de seus avanços patrimoniais e tecnológicos, avaliando sua importância para a economia e sociedade brasileiras. Avaliando o aspecto conotativo, podemos reconhecer que a peça procura estabelecer uma relação continente (a nação)/ conteúdo (a empresa) e vincular-se entranhadamente à construção do país por meio da contraposição e integração de duas histórias: a nacional e a da empresa, mas também de passado (representado na pintura) e presente de modernidade e avanço (a foto de instrumentos de laboratório e o texto de chamada e as margens imitando letreiro de néon).

A figura 3, por fim, traz para o espectador várias reproduções do quadro de Pedro Américo superpostas, numa criativa associação com a mensagem referência, que é o grupo Nashua, especializado em tecnologia 
de fotocópias. Num texto bem humorado, louva o autor do quadro como quem "soube reproduzir e para sempre o momento mais emocionante da história do Brasil", mas ao mesmo tempo pede desculpas e afirma que isso

Figura 3 - Visão v. 4, n. $40(28 / 2 / 72)$

\section{Já não se fazem reproduções como antigamente...}

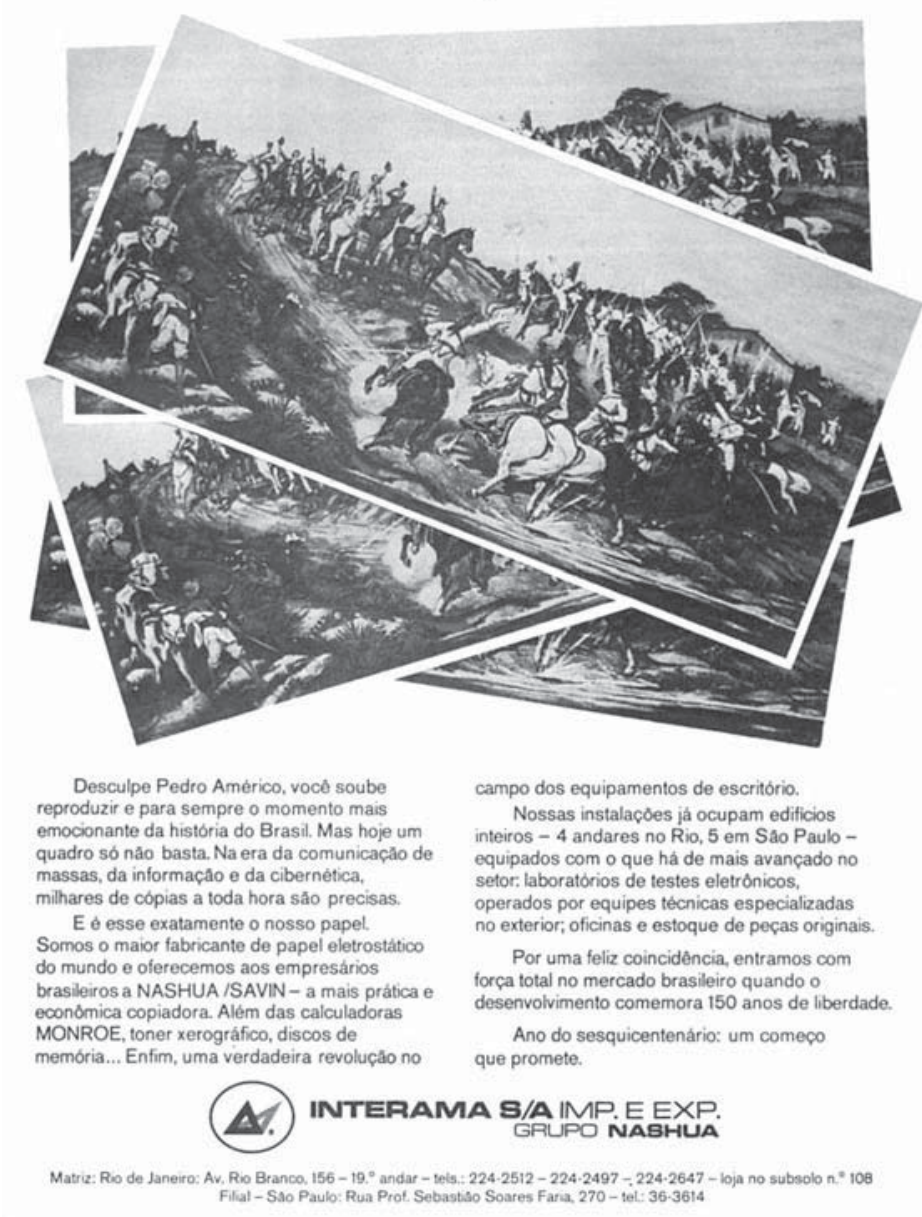

Cad. Cedes, Campinas, vol. 25, n. 67, p. 319-331, set./dez. 2005

Disponível em <http://www.cedes.unicamp.br> 
não é mais suficiente hoje, tempo da cibernética em que milhares de reproduções são exigidas. Esse é o gancho para a empresa integrar-se ao ritual de identificação: possibilitar, através da sua tecnologia, a propagação da imagem canônica de um dos mitos fundadores da comunidade nacional, reconstruído por Pedro Américo em versão oficial.

Estamos diante da referência a três empresas de grande porte, que podem ser identificadas como colaboradoras, participantes ou no mínimo coniventes com o regime. Não que isso deva servir para fazer juízo de valor sobre as mesmas: trata-se, sim, de criar elementos para compreender a lógica de funcionamento da sociedade sob a ditadura, bem como de buscar elementos para decifrar o uso da história para os objetivos tanto políticos quanto econômicos da propaganda. Em comum, todas as peças têm a referência à versão oficial da história, tanto no que se refere à aceitação do Sete de Setembro e de D. Pedro I como encarnações da Independência, quanto à aceitação e propagação das representaçôes como verdade histórica e não como leituras da mesma a partir de informações posteriores, fragmentadas e interessadas. Todas as empresas investem suas contas de publicidade para, simbolicamente, estar na festa e ser parte do que está sendo comemorado, identificar-se com o que constitui, em termos apenas econômicos, o seu mercado. Duas das peças (como a maioria das que vieram a público) trazem o logotipo oficial do Sesquicentenário, que significa uma adesão à campanha lançada oficialmente pelo Estado brasileiro pela comemoração da data. Por fim, todas são reverentes a D. Pedro e à Proclamação da Independência e aderem à visão da história oficial esculpida em cinzel nacionalista, embora a historiografia nesse momento já permitisse uma interpretação crítica.

Respeitadas as dimensões desse texto, pretendeu-se discutir e exemplificar o uso da propaganda para o ensino da história e das humanidades, tanto como expressões da experiência histórica quanto - ao mesmo tempo - veículos de um conhecimento histórico elaborado anteriormente e divulgado para o grande público, compondo um trabalho educativo nãoescolar, que é capaz de informar e de formar noçôes históricas sem que estejamos atentos ou preparados para isso, nós e nossos alunos, na maior parte das vezes. Não se tratou aqui de ter a pretensão de ensinar ao professor como proceder para ensinar, mas sim de dar sugestóes e referenciais para que o mestre possa cada vez mais lidar com o conhecimento não como reprodutor, mas como co-pensador, como produtor de crítica e de análise 
sobre todo tipo de material que cai em suas mãos e na de seus alunos como elemento para o processo educativo.

Recebido em maio de 2005 e aprovado em setembro de 2005.

Notas

1. Usaremos aqui indistintamente os termos propaganda e publicidade: embora tenham significados tendenciais próprios - a propaganda refere-se principalmente à divulgação de idéias, enquanto a publicidade tende a significar a divulgação de produtos - , creio que é impossível separar a venda de produtos da venda de idéias, e muito difícil separar a venda de idéias da de produtos, o que tem inclusive feito do marketing político um conversor de personalidades políticas em produtos.

2. São múltiplas as possibilidades de datar a independência, conforme o sujeito histórico que se quer dar destaque: o Sete de Setembro é somente a narrativa vencedora desse processo. Sobre esse assunto, ver Lyra (1995).

3. Este debate é seguido e estudado por Carvalho (1993).

\section{Referências bibliográficas}

BARTHES, R. Societé, imagination, publicité. In: Barthes, R. Oeuvres completes (1966-1973). Paris: Seuil, 1994. t. 2, p. 173.

BARTHES, R. The semiotic challenge. New York: Hill and Wanf, 1988.

CARVALHO, J.M. A formação das almas: o imaginário da República no Brasil. São Paulo: Cia das Letras, 1993.

LYRA, M.L.V. Memória da Independência: marcos e representações simbólicas. Revista Brasileira de História, São Paulo, v. 15, n. 29, p. 173-206, 1995.

MARX, K. O caráter fetichista da mercadoria e seu segredo. In: MARX, K. O capital. 2. ed. São Paulo: Nova Cultural, 1985. v. 1. 